\title{
Synthesis of structured phospholipids by immobilized phospholipase A2 catalyzed acidolysis
}

\author{
Vikbjerg, Anders Falk; Vikbjerg, Anders Falk; Xu, Xuebing
}

Published in:

Journal of Biotechnology

Link to article, DOI:

10.1016/j.jbiotec.2006.11.006

Publication date:

2007

Link back to DTU Orbit

Citation (APA):

Vikbjerg, A. F., Vikbjerg, A. F., \& Xu, X. (2007). Synthesis of structured phospholipids by immobilized phospholipase A2 catalyzed acidolysis. Journal of Biotechnology, 128(3), 545-554.

https://doi.org/10.1016/j.jbiotec.2006.11.006

\section{General rights}

Copyright and moral rights for the publications made accessible in the public portal are retained by the authors and/or other copyright owners and it is a condition of accessing publications that users recognise and abide by the legal requirements associated with these rights.

- Users may download and print one copy of any publication from the public portal for the purpose of private study or research.

- You may not further distribute the material or use it for any profit-making activity or commercial gain

- You may freely distribute the URL identifying the publication in the public portal

If you believe that this document breaches copyright please contact us providing details, and we will remove access to the work immediately and investigate your claim 
$10 *$ Correspondence:

11 A.F. Vikbjerg, BioCentrum-DTU, Technical University of Denmark, Building 221, DK-

122800 Kgs. Lyngby, Denmark

13 Tel. +4545252614

$14 \quad$ Fax. +4545884922

15 E-mail address: afv@biocentrum.dtu.dk (Anders Falk Vikbjerg)

16 Reprint request to Xuebing Xu, xx@biocentrum.dtu.dk

17

18

19

phospholipase $\mathrm{A}_{2}$ catalyzed acidolysis

\section{Anders Falk Vikbjerg*, Huiling Mu, and Xuebing Xu}

Running title: PLA $A_{2}$ catalyzed synthesis of structured phospholipids 


\section{Abstract}

Acyl modification of the sn-2 position in phospholipids (PLs) was conducted by

3 acidolysis reaction using immobilized phospholipase $\mathrm{A}_{2}\left(\mathrm{PLA}_{2}\right)$ as the catalyst. In the

4 first stage we screened different carriers for their ability to immobilize PLA2. Several

5 carriers were able to fix the enzyme and maintain catalytic activity; however the final

6 choice of carrier for the continued work was a non-ionic weakly polar macroreticular

7 resin. Response surface methodology was applied to evaluate the influence of substrate

8 ratio, reaction temperature and water addition during acidolysis reaction between

9 caprylic acid and soybean phosphatidylcholine (PC). Reaction temperature and water

10 addition had significant effect on acidolysis reaction, however no effect was observed

11 for substrate ratio (mol caprylic acid/mol PC) in range tested. In general an inverse

12 relationship between incorporation of caprylic acid and PC recovery was observed.

13 Highest incorporation obtained during acidolysis reactions was 36\%. Such

14 incorporation could be obtained under reaction temperature, $45^{\circ} \mathrm{C}$; substrate ratio, 9

$15 \mathrm{~mol} / \mathrm{mol}$ caprylic acid/PC; and water addition of 2\%; $30 \mathrm{wt} \%$ immobilized enzyme; and

16 reaction time, $48 \mathrm{~h}$. The yield under these conditions was however only $29 \%$.

17 Lysophosphatidylcholine (LPC) was the major by-product formed during the reaction.

18 Incorporation of acyl donor into LPC was very low $(<4 \%)$, which indicates that acyl

19 migration is only a minor problem for $\mathrm{PLA}_{2}$ catalyzed synthesis reaction. Conjugated

20 linoleic acid and docosahexaenoic acid were also tested as acyl donors, and were able to

21 be incorporated into PC with 30 and $20 \%$, respectively.

22 Keywords: Immobilization; PLA 2 catalyzed synthesis; response surface methodology;

23 solvent-free system; structured phospholipids. 


\section{1. Introduction}

2

Different enzymes can be used to tailor phospholipids (PLs) with defined fatty acid composition at the sn-1 and sn-2 positions. Using enzymatic acyl exchange it would be possible to acquire PLs for specific application requirements in food, pharmaceuticals and cosmetics by altering the technical or physiological properties of the natural compounds. Most of the work in this direction focuses on incorporation of saturated fatty acids (including both medium chain and long chain) or polyunsaturated fatty acids into PLs (Hossen et al., 2005; Lyberg et al., 2005; Reddy et al., 2005; Vikbjerg et al., 2005). The interest in the incorporation of saturated fatty acids is mainly to improve the heat stability, emulsifying properties and oxidation stability of the PLs (Chmiel et al., 1999; Pedersen, 2001), while the incorporation of polyunsaturated fatty acids is due to the claimed health promoting effects (Takahashi and Hosokawa, 2001).

Compared to enzymatic acyl exchange at the sn-1 position of PLs, the enzymatic acyl exchange in the sn-2 position has received less attention. Porcine pancreatic phospholipase $\mathrm{A}_{2}\left(\mathrm{PLA}_{2}\right)$, which is the most commonly used enzyme for modification of PLs at the sn-2 position, is considerably more difficult for synthesis in comparison with lipases from microbial sources commonly used for modification of the sn-1 position of PLs. Pancreatic PLA 2 has requirement of calcium ions and a water activity above 0.2 to be catalytically active, which means that low yields can be expected compared to lipase-catalyzed reactions that can function in nearly anhydrous reaction systems without the presence of calcium ions (Pernas et al., 1990, Adlercreutz et al, 2003). 
Despite these problems there remains a great interest in using $\mathrm{PLA}_{2}$ for PL

2 synthesis as fatty acids resided in the secondary position of PLs may have particular

3 important influence on nutritional and medical functions (Takahashi and Hosokawa, 4 2001).

6 (liquid solution), but some attempts have previously been made to immobilize the 7 enzyme (Aura et al.,1995; Doig and Diks, 2003; Härrod and Elfman, 1995; Hossen et al.

8 2005; Lyberg et al. 2005). Main reason to use immobilized enzymes is the ability to

9 isolate the biocatalyst from reaction mixture as well as to improve the stability. Some of

10 the carriers selected in these previous studies would however not be suitable if having

11 larger-scale production in mind. Enzymes immobilized on celite and certain other

12 porous or powder inert materials have good initial activity, but are often difficult to

13 handle or have insufficient enzymatic and physical stability in industrial processes

14 (Eigtved, 1992). Dust formation, displacement of the enzyme from the carrier, and high

15 pressure drops in packed bed columns are some of the problems that can occur using

16 these types of carriers. Polymer or resin based carriers have been described, which

17 offers strong adsorption, high activity, and stability of enzymes, which would

18 accommodate enzymes and transport lipid substrate without major diffusion problems

19 (Eigtved, 1992).

20 Most work described for the PLA 2 catalyzed synthesis of structured PLs are 21 based on esterification of lyso-PLs in organic solvent (Adlercreutz et al., 2003; Guo et 22 al., 2005). In order to obtain lyso-PLs for this type of reaction it would require a 23 hydrolysis step of the PL and subsequent purification step to remove free fatty acids.

24 Direct transesterification (acidolysis) of PL with acyl donor would avoid these 
1 additional steps as reaction can be performed in a single step. Some attempts have

2 previously been made for transesterification; however in general the incorporation of

3 fatty acids into the sn-2 position is rather low (<15\%) (Aura et al., 1995; Hossen et al., 4 2005; Park et al., 2001).

In this study we screened different carriers for immobilization of PLA2. A

6 promising carrier was selected and further experiments were performed to maximize

7 catalytic activity of the immobilized enzyme. The immobilized $\mathrm{PLA}_{2}$ was subsequently

8 used for synthesis of structured PLs under solvent-free conditions. The reaction scheme

9 for PLA 2 -catalyzed acidolysis is depicted in Fig. 1. Different parameters were examined

10 for their influence on incorporation and PL distribution during PLA 2 catalyzed synthesis

11 of structured PLs. Response surface methodology was used to assist the evaluation.

\section{Materials and Methods}

\subsection{Materials}

Epikuron 200 (PC, 93\%) was purchased from Degussa Texturant Systems Deutchland GmbH \& Co. KG (Hamburg, Germany). The fatty acid composition $19(\mathrm{~mol} \%)$ of PC can be seen in Table 1 . Caprylic acid (C8:0, purity 97\%) was purchased 20 form Riedel-de-Haen (Seelze, Germany). Conjugated linoleic acid (CLA, purity 80\%) 21 consisting of $38.8 \% 9 \mathrm{c}, 11 \mathrm{t}$ isomer and $38.8 \% 10 \mathrm{t}, 12 \mathrm{c}$ isomer was provided by Natural 22 ASA (Hovdebygda, Norway). 4,7,10,13,16,19 all cis-Docosahexaenoic acid (DHA, 23 purity 99+ \%) was purchased from Loradan Fine Chemicals (Malmö, Sweden). Porcine 24 pancreatic $\mathrm{PLA}_{2}$ (Lecitase $10 \mathrm{~L}, 10.000 \mathrm{U} / \mathrm{ml}$ ) was supplied by Novozymes A/S 
1 (Bagsvaerd, Denmark). Carrier materials and their suppliers are listed in table 2. All

2 solvent and chemicals were of analytical grade.

3

4 2.2. Immobilization of PLA2

5

6 Varying amounts of $\mathrm{PLA}_{2}$ solution was added to $5 \mathrm{ml}$ buffer ( $10 \mathrm{mM}$ Tris-HCl,

$7 \quad 10 \mathrm{mM} \mathrm{CaCl}_{2}, \mathrm{pH} 8$ ) followed by the addition of $250 \mathrm{mg}$ carrier. The enzyme solutions

8 containing the carrier were incubated overnight by end-over-end mixing at room

9 temperature followed by centrifugation at $4000 \mathrm{rpm}$ for 5 minutes. The fixation level

10 was estimated subtracting the protein remaining in the supernatant after binding

11 compared to the initial protein concentration. Protein was determined according to the

12 method of Lowry et al. (1951) using Bovine Serum albumin (BSA) as the standard.

13 Enzyme preparation was removed by filtration and subsequently dried overnight in

14 fume hood. Immobilized $\mathrm{PLA}_{2}$ was stored at $5^{\circ} \mathrm{C}$ prior to use.

16 2.3. Hydrolytic activity of PLA2.

17

18 Evaluation of the catalytic activity was determined by hydrolysis of PC as 19 described by Kim et al. (2001). Reactions were carried out in an ethanol-buffer (10 mM 20 Tris-HCl, $10 \mathrm{mM} \mathrm{CaCl}_{2}, \mathrm{pH}$ 8.0) (ratio, 70:30) with $0.4 \mathrm{~g} \mathrm{PC/} \mathrm{ml}$. Capped flasks 21 containing the PC solution were incubated in water bath with magnetic stirring (300 rpm) at $40^{\circ} \mathrm{C}$. Hydrolysis reactions were initiated by the addition of PLA 2 . Samples were withdrawn during progress in reaction, and analyzed by TLC-FID. The activity 
1 was defined as the amount of LPC produced per min, and specific activity was defined

2 as the amount of LPC produced per min and mg protein.

3

$4 \quad$ 2.4. Acidolysis reaction

5

6 Reactions between fatty acid and PC were carried out using a $1 \mathrm{~g}$ reaction

7 mixture in $5 \mathrm{ml}$ glass vials. Vials were incubated in a water bath with magnetic stirring

8 (300 rpm) and reactions were initiated by the addition of $300 \mathrm{mg}$ immobilized PLA 2

9 (carrier: Amberlite XAD7; $72 \mathrm{mg} \mathrm{PLA}_{2} / \mathrm{g}$ carrier). After reactions, samples were

10 withdrawn from the reaction mixture for analysis. A three-level three-factor fractional

11 experiment with 2 star points (17 experiments) was carried out. The three factors chosen

12 were: reaction temperature $\left({ }^{\circ} \mathrm{C}\right)$, water addition ( $\mathrm{wt} \%$ based on total substrate), and

13 substrate ratio (mol/mol caprylic acid/PC). The incorporation of caprylic acid into PC,

14 and the PL distribution (PC, LPC and glycerophosphorylcholine (GPC)) were used as

15 responses. In table 1 are listed the factors used, the parameter ranges applied, and the 16 responses.

17

2.5. Analysis methods

19

Analytical separations PL species and fatty acids were performed on Silica Gel 60

21 thin-layer plates (20cm x 20cm, Merck, Darmstadt, Germany). After development in

22 chloroform-methanol-water $(65: 35: 5, \mathrm{v} / \mathrm{v})$, the plate was sprayed with $0.2 \%$ of $2,7-$

23 dichloroflourescein in ethanol (96\%), making the lipid bands visible under UV-light.

24 Bands representing PC and LPC were scraped off and methylated by BF3 for analysis 
1 on a HP6890 series gas-liquid chromatograph (Hewlett-Packard, Waldbronn, Germany)

2 equipped with a flame-ionization detector (FID) (Vikbjerg at al., 2005). reactions using thin layer chromatography coupled with flame ionization detection 5 (TLC-FID). Samples were spotted onto silica gel chromarods (Chromarod SIII, Iatron 6 Laboratories Inc., Tokyo, Japan) and developed in a mixture of 7 chloroform/methanol/water (42:22:3, v/v/v). After developing, chromarods were dried 8 at $120^{\circ} \mathrm{C}$ for $5 \mathrm{~min}$. Chromarods were then placed into the TLC-FID analyzer (Iatroscan 9 MK6s, Iatron Laboratories Inc., Tokyo, Japan) and scanned at a rate of 30s/rod. Flow 10 rates of $160 \mathrm{ml} / \mathrm{min}$ for hydrogen and $21 / \mathrm{min}$ for air were used during analysis. Peaks 11 were identified by external standards.

\subsection{Statistical analysis}

16 Significance of the results was established at $\mathrm{P} \leq 0.05$.Differences in the responses were

17 determined by one-way analysis of variance, where $95 \%$ confidence intervals were calculated from pooled standard deviations (SD) using software Microsoft Office Excel 2003 (Microsoft Corporation, Redmond, WA). The computer program Modde 6.0

20 (Umetri AB, Umeå, Sweden) was used to aid the statistical design of the factorial 21 experiments and to fit and analyze the data by multiple regressions. The fit of the 22 models were evaluated by the coefficient of determination $\left(\mathrm{R}^{2}\right)$ and analysis of variance (ANOVA). 


\section{$1 \quad 3$. Results and discussion}

2

\section{3}

4

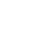

\subsection{Screening for carrier materials}

In order to have a practical approach for $\mathrm{PLA}_{2}$ catalyzed production of structured PLs the enzyme is preferred in the immobilized form. This would make it possible in sight to develop a continuous process as the enzyme can easily be recovered and reused, and would make the process more economically feasible. Of the various methods for immobilization physical absorption of the enzyme onto solid support remains the simplest, least expensive, and least labour-intensive procedure. Secreted $\mathrm{PLA}_{2}$ requires $\mathrm{Ca}^{2+}$ as co-factor; however the concentration of $\mathrm{Ca}^{2+}$ strongly influences the synthetic activity of these enzymes (Pernas et al., 1990). High concentrations of $\mathrm{Ca}^{2+}$ give rise to sever inhibition of synthesis reactions. In some cases the dependence of $\mathrm{Ca}^{2+}$ is simply overcome by doing the immobilization in buffer containing $\mathrm{CaCl}_{2}$ (Egger et al., 1997; Aura et al, 1995; Lyberg et al. 2005). Pernas et al. (1990) reported that initial rate of PL synthesis conducted in organic solvent was dependent on the $\mathrm{pH}$ of the last aqueous solution in which the enzymes were exposed; however the maximum conversion was not dependent on the $\mathrm{pH}$ in the range 4-11. In most cases buffer has been adjusted to $\mathrm{pH} 8$, when porcine pancreatic $\mathrm{PLA}_{2}$ have been used as catalyst. Conditions for the buffer used in the current study were selected based on recommendations from the previous studies mentioned above.

Seven different carriers were examined for their ability to immobilize PLA 2 . Characteristics of enzyme carriers screened are presented in table 2. In all cases, the immobilization procedure was the same. Table 3 shows the protein absorption to 
1 different carriers. High fixation of $\mathrm{PLA}_{2}$ to the carriers was observed except for Accural

2 EP100 and Lewatit VP1600. These two carriers were also very hydrophobic, and did

3 not suspend in the enzyme solution as the other carriers, but floated to the top. By pre-

4 wetting these carriers with ethanol prior to immobilization it was possible to suspend

5 these carriers in the enzyme solution, which also resulted in an increase of the fixation

6 level of $\mathrm{PLA}_{2}$ (table 3). The three carriers immobilized with $\mathrm{PLA}_{2}$ having the highest

7 protein fixation (Amberlite XAD7, Duolite A568, and Superlite DAX8) were tested for

8 their hydrolytic activity (table 3 ). As there was seen some differences in the enzyme

9 fixation, the immobilized enzymes were added to the reaction mixture with similar

10 protein loading. One-way analysis of variance showed that there was significant

11 difference in catalytic activity of $\mathrm{PLA}_{2}$ when immobilized on these different carriers

$12(\mathrm{p}<0.01)$. Having Amberlite XAD7 and Superlite DAX8 as carriers resulted in

13 significant higher specific activity as compared to having Duolite A568 as the carrier;

14 however there was no significant difference in the specific activity between Amberlite

15 XAD7 and Superlite DAX8. Amberlite XAD7 had the highest protein fixation though,

16 which means that lower dosage requirements were needed to obtain the same

17 conversion degree. From considerations above Amberlite XAD7 was found to be a

18 suitable carrier and was selected for the further study.

\subsection{Conversion efficiency of the immobilized enzyme}

Binding of enzyme to the carriers and the total amount bound will depend on

23 the initial concentrations of the catalyst and the carrier, and ratio of the two components.

24 In Fig.2 the influence of initial enzyme /carrier ratio on fixation level to Amberlite 
1 XAD7 is depicted. Protein binding to the carrier increased with increased ratio between

2 enzyme and carrier. However activity only increased with increasing fixation level until

3 a certain protein loading was reached; and the specific activity decreased with increase

4 in fixation level of $\mathrm{PLA}_{2}$ (Fig. 3A). Highest specific activity was observed at low

5 fixation level of $\mathrm{PLA}_{2}$. At high enzyme load only a fraction of the enzyme seems to be

6 involved in the catalytic reaction. Higher enzyme load would contribute to increased

7 limitation of substrate diffusion and therefore decreasing efficiency. From Fig. 3A it

8 seems that an initial enzyme/carrier ratio of approximately $100 \mathrm{mg} / \mathrm{g}$ would give the

9 optimal fixation of $\mathrm{PLA}_{2}$ in terms of activity. Influence of enzyme loading on activity

10 and specific activity with this fixation level was examined (Fig. 3B). This was mainly to

11 confirm that the results obtained above were valid, and that the decline in activity was

12 not related to for example substrate limitations. As expected the activity increased with

13 increased enzyme dosage, and the specific activity was constant. For the subsequent

14 acidolysis reactions $\mathrm{PLA}_{2}$ was immobilized to Amberlite XAD7 with an initial

15 enzyme/carrier ratio $100 \mathrm{mg} / \mathrm{g}(72 \mathrm{mg} / \mathrm{g}$ enzyme fixed/carrier).

\section{3. $P L A_{2}$ catalyzed acidolysis reaction}

Reactions were performed in a single step, having both hydrolysis and

20 esterification reactions that occur simultaneously. The fatty acids resided in the sn-2

21 position of PLs will therefore be a mixture of original fatty acids and the ones to be incorporated. Theoretically the presence of original fatty acids can be minimized by

23 having high substrate ratio (mol acyl donor/mol PL). A preliminary study was

24 conducted to evaluate incorporation and PL distribution during the time course of 
1 acidolysis reaction between PC and caprylic acid. Reaction conditions selected were a

2 substrate ratio of $6 \mathrm{~mol} / \mathrm{mol}$ caprylic acid/PC, together with $30 \%$ enzyme dosage at

$340^{\circ} \mathrm{C}$. Some water was added to the reaction mixture $(0.75 \%)$, as this enzyme requires

4 some water to main activity (Adlercreutz et al., 2003). The results showed that, after

$572 \mathrm{~h}$, it was possible to have $15 \%$ incorporation of caprylic acid into PC (Fig. 4A).

6 However with increasing incorporation, the recovery of PC decreased. Complexity of

7 the acidolysis reaction makes it difficult to predict the influence of different parameters

8 on incorporation and PL distribution. A statistical experimental design was therefore set

9 up with the assistance of response surface methodology (RSM) to evaluate the influence

10 of individual parameters, as well as their interactions, on incorporation and PL

11 distribution. Reaction temperature, substrate ratio and water addition were selected as

12 variables, whereas enzyme dosage and reaction time were held constant in the current

13 study. From Fig. 4B it can be observed that with a reaction more than $48 \mathrm{~h}$ there was

14 only seen a small progress in the reaction. From a process point of view it would be

15 desirable to have as low a reaction time as possible. Responses and variable settings in

16 Table 4 were fitted to each other with multiple regressions. The best-fitting models were

17 determined by multiple regression and backward elimination, whereby insignificant

18 factors and interactions were removed from the models. The statistics for the model

19 coefficients and probability values for response variables are presented in table 5 . The

20 coefficient of determination $\left(\mathrm{R}^{2}\right)$ of the models were $0.95,0.99,0.98,0.67$ for the four

21 responses, i.e. incorporation into PC, PC content, LPC content and GPC content,

22 respectively. Models with acceptable qualities should have $\mathrm{R}_{2}>0.8$. Most of models

23 therefore represent real relationship between responses and the reaction parameters.

24 According to the analysis of variance there was no lack of fit for the generated models. 
1 Observed and predicted values were sufficiently correlated except for experiment no.1,

2 which was treated as an outlier.

Water addition was the most significant factor on the $\mathrm{PLA}_{2}$ catalyzed acidolysis

4 reactions in terms of incorporation and recovery (table 5). A continuous increase in the

5 incorporation was observed until water level of $2 \%$ (Fig. 5A). Higher water addition had

6 no significant effect on incorporation. The recovery of PC decreased with increased

7 water addition (Fig.5B). With increase of water in the reaction system both LPC and

8 GPC increased. GPC forms if acyl chain of LPC molecule migrates from the sn-1

9 position to the sn-2 position, and the formed 2-acyl LPC is hydrolyzed by PLA2. It was

10 previously demonstrated that water content had no effect on the incorporation in

11 solvent-free system during lipase-catalyzed acidolysis reaction (Vikbjerg et al., 2005),

12 which is in contrast to $\mathrm{PLA}_{2}$ catalyzed acidolysis reaction. With both types of enzyme,

13 the recovery of PC decreases with increasing water content due to parallel hydrolysis

14 reaction. Water seems to have a complex role in terms of compromising enzyme

15 activity, hydrolysis side reactions, reaction rate, and extent of incorporation. As PLA2

16 require a higher water activity to function as compared to lipases, the yield is expected

17 to be lower (Adlercreutz et al., 2003).

18 Reaction temperature also had significant effect on the acidolysis reaction.

19 Maximum incorporation was observed at $45^{\circ} \mathrm{C}$ (Fig.6A). At higher and lower

20 temperatures there was a decrease in the incorporation of caprylic acid into PC. The

21 lowest yield was obtained at $45^{\circ} \mathrm{C}$ (Fig.6B). At higher and lower temperatures PC

22 content increased. In general an increase in temperature increases the rate of all

23 chemical reactions, including those catalyzed by enzymes, but at the same time it

24 increases the rate of denaturation of enzyme protein. These processes probably explain 
1 the characteristic temperature profile of $\mathrm{PLA}_{2}$ and high value for the second order value

2 in the models. Park et al. (2000) examined the effect of reaction temperature on

3 transesterification of PC and ethyl esters of EPA in toluene, and found that maximum

4 reaction rate and yield were at $50^{\circ} \mathrm{C}$. Enzyme activity was observed to drop sharply

5 above $50^{\circ} \mathrm{C}$. Egger et al. (1997) reported that during synthesis of PC from LPC highest

6 reaction rate was observed at $40^{\circ} \mathrm{C}$. At this temperature there was however observed a

7 decrease in the amount of PC and LPC during the enzymatic reaction. This decrease

8 was found to be due to formation of GPC. It was claimed that at this high temperature

9 GPC formation occurred due to acyl migration. In this study the temperature had an

10 effect on formation of GPC. Highest content of GPC was at $45^{\circ} \mathrm{C}$. With higher LPC

11 content in reaction system formation of GPC seems to increase especially at elevated 12 temperatures.

13 Substrate ratio had no significant effect on either incorporation of caprylic acid

14 or the PL distribution, and no interaction was seen for this factor. Even though no

15 differences are seen in the relative PL distribution, it should be remembered that the PL

16 concentration is higher at lower substrate ratios. In terms of production it would be

17 recommended to have low substrate ratio.

18 Highest incorporation was obtained by having reaction temperature, $45^{\circ} \mathrm{C}$; water

19 addition 2\%; and substrate ratio, $9 \mathrm{~mol} / \mathrm{mol}$ caprylic acid/PC. Under these conditions

20 the PC accounted for $29 \%$ of the PL fraction. The incorporation of caprylic acid into

21 LPC was also examined, however was less than $4 \%$ for all samples (data not shown), and therefore no attempts were made to model these data. 


\subsection{Reactivity of different fatty acids}

2

Different fatty acids may be applied as acyl donor for acidolysis reaction.

However the fatty acids usually result in different reactivity, due to fatty acid specificity or possible inhibition effects. Under the same conditions, different fatty acids often result in different incorporation into PLs or different yields. Reaction rates have been reported to be the same for saturated fatty acids of length between 6 and 12 carbon atoms, but they were lower for myristic and palmitic acids (Egger et al. 1997). Highest reaction rate was obtained with oleic acid, but higher degree of unsaturation resulted in lower reaction rates. In this study we compared the incorporation of DHA and CLA with that of caprylic acid under similar reaction conditions $\left(\mathrm{Te}, 45^{\circ} \mathrm{C} ; \mathrm{Wa}, 2 \% ; \mathrm{Sr}, 3\right.$ $\mathrm{mol} / \mathrm{mol}$ fatty acid/PL). The incorporations of the different fatty acids into PC are presented in table 1. CLA resulted in the highest degree of incorporation, followed by caprylic acid and DHA. PLA 2 showed little discrimination toward the two main isomers of CLA (data not shown). With CLA as acyl donor the PL distribution after reaction was 21,74 , and 5\% for PC, LPC and GPC, respectively. With DHA as acyl donor the PL distribution was 22, 77, and 1\% for PC, LPC and GPC respectively. Yields were thus lower when using CLA and DHA as acyl donors, however the formation of GPC was also lower as compared to reactions performed with caprylic acid (see table 4, experiment no.13). The results indicate that caprylic acid may cause more acyl migration in the reaction system compared to DHA and CLA, however further experiments would be required to verify this observation.

In conclusion PC with modified fatty acid profile can be produced by $\mathrm{PLA}_{2}$ catalyzed acidolysis. Water addition and reaction temperature were shown to have 
1 significant effect on both incorporation and yield. Both reaction temperature and water

2 addition had an inverse relationship between incorporation and recovery of PC.

3 Substrate ratio showed no effect on the PL distribution. Incorporation of caprylic acid

4 into PC could reach $36 \%$ accounting for $29 \%$ of the PL fraction. Incorporation of new

5 fatty acids was shown to depend on acyl donor. Polyunsaturated fatty acids DHA and

6 CLA were incorporated into PC with 30 and 20\%, respectively.

7

\section{Acknowledgements}

10 This project was financially supported by the Danish Technical Research Council 11 (STVF) and the Center for Advanced Food Studies (LMC).

\section{References}

14 Adlercreutz, P., Lyberg, A.-M., Adlercreutz, D., 2003. Enzymatic fatty acid exchange in 15 glycerophospholipids. Eur. J. Lipid Sci. Technol. 105, 638-645.

16 Aura, A.-M., Forssell, P., Mustranta, A., Poutanen K., 1995. Transesterification of soy 17 lecithin by lipase and phospholipase. J. Am. Oil Chem. Soc. 72, 1375-1379.

18 Chmiel, O., Melachouris, N., Tritler, H. Process for the interesterification of 19 phospholipids. US Patent 5,989,599.

20 Doig, S.D., Diks, R.M.M, 2003. Toolbox for exchanging constituent fatty acids in 21 lecithin. Eur. J. Lipid Sci. Technol. 105, 359-367.

22 Egger, D., Wehtje, E., Adlercreutz, P., 1997. Characterization and optimization of 23 Phospholipase $\mathrm{A}_{2}$ catalyzed synthesis of phosphatidylcholine. Biochim. Biophys. Acta $1343,76-84$. 
1 Eigtved, P., 1992. Enzymes and lipid modification. In: Padley, F.B. (Ed.), Advances in applied lipid research, vol. 1, JAI Press Ltd, London, 1-64.

3 Guo, Z., Vikbjerg, A. F., Xu, X., 2005. Enzymatic modification of phospholipids for functional applications and human nutrition. Biotechnol. Advances, 23, 203-259.

5 Härröd, M., Elfman, I., 1995. Enzymatic synthesis of phosphatidylcholine with fatty 6 acids, isooctane, carbon dioxide, and propane as solvent. J. Am. Oil Chem. Soc. 72, 7

Lyberg, A. M., Adlercreutz, D., Adlercreutz, P., 2005. Enzymatic and chemical synthesis of phosphatidylcholine regioisomers containing eicosapentaenoic acid or docosahexaenoic acid. Eur. J. Lipid Sci. Technol. 107, 279-290.

Park, C.W., Kwon, S.J., Han, J.J., Rhee, J.S., 2000. Transesterification of phosphatidylcholine with eicosapentaenoic acid ether ester using phospholipase A2 in organic solvent. Biotechnol. Lett. 22, 147-150.

Pedersen, K.B., 2001. Interesterification of phospholipids. US patent 6,284,501.

Pernas, P., Oliver, J.L., Legoy, M.D., Bereziat, G., 1990. Phospholipid synthesis by extracellular phospholipase $\mathrm{A}_{2}$ in organic-solvents. Biochem. Biophys. Res. Commun. 168, 644-650. 
1 Reddy, J. R. C., Vijeeta, T., Karuna, M. S. L., Rao, B. V. S. K., Prasad, R. B. N., 2005. Lipase-catalyzed preparation of palmitic and stearic acid-rich phosphatidylcholine. J. Am. Oil Chem. Soc. 82, 727-730.

4 Takahashi, K., Hosokawa, M., 2001. Production of tailor-made polyunsaturated 5 phospholipids through bioconversions. J. Liposome Res. 11, 343-353.

6 Vikbjerg, A.F., Mu, H., Xu, X., 2005. Parameters affecting incorporation and by7 product formation during the production of structured phospholipids by lipasecatalyzed acidolysis in solvent-free system. J. Mol. Catal. B-Enz 36, 14-21. 
1 Table 1 Fatty acid distribution in PC and structured PCs (mol\%)

Structured $\mathrm{PC}^{\mathrm{a}}$

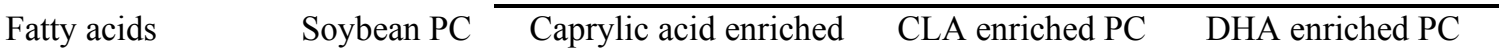
PC

\begin{tabular}{lcccc}
\hline $8: 0$ & - & 25.3 & - & - \\
$16: 0$ & 12.8 & 13.0 & 13.0 & 12.2 \\
$18: 0$ & 3.9 & 3.2 & 3.0 & 3.2 \\
$18: 1$ & 9.4 & 7.5 & 9.1 & 8.3 \\
$18: 2$ & 65.5 & 45.3 & 38.6 & 48.9 \\
$18: 3$ & 8.1 & 5.7 & 6.4 & 7.3 \\
CLA (all isomers) & - & & 30.0 & - \\
$22: 6$ & - & & - & 20.2 \\
\hline
\end{tabular}

2

$3{ }^{a}$ Reaction conditions: Reaction temperature, $45^{\circ} \mathrm{C}$, Water addition, $2 \%$; Substrate ratio, $3 \mathrm{~mol} / \mathrm{mol}$, 4 enzyme dosage, $30 \%$; Reaction time, $48 \mathrm{~h}$.

5 
Table 2. Carriers screened and their characteristics

\begin{tabular}{|c|c|c|}
\hline Carrier & Supplier & General description \\
\hline Amberlite XAD7 & $\begin{array}{l}\text { Sigma-Aldrich Chemie } \\
\text { GmbH, Steinheim, Germany }\end{array}$ & $\begin{array}{l}\text { Nonionic weakly polar macroreticular resin (matrix: acylic } \\
\text { ester), Particle size: } 0.25-0.85 \mathrm{~mm} \text { (wet) }\end{array}$ \\
\hline Superlite DAX8 & Supelco, Bellefonte, USA & $\begin{array}{l}\text { Resin with moderate polarity (matrix: acrylic ester), Particle } \\
\text { size: } 0.25-0.45 \mathrm{~mm}\end{array}$ \\
\hline Celite 545 & BHD, Poole, UK & Diatomaceous Earth, Particle size: 0.02-0.1 mm \\
\hline Dowex 50W & $\begin{array}{l}\text { Dow Chemical Company, } \\
\text { Michigan, USA }\end{array}$ & $\begin{array}{l}\text { Strongly acidic cation exchange (maxtrix:resinstyrene- } \\
\text { divinylbenzene; functional group: sulfonic acid), Particle size: } \\
0.15-0.30 \mathrm{~mm}\end{array}$ \\
\hline Lewatit VPOC1600 & $\begin{array}{l}\text { Lanxess AG, Leverkusen, } \\
\text { Germany }\end{array}$ & $\begin{array}{l}\text { Divinyl benzene crosslinked polymer (Marix: methacrylate), } \\
\text { Particle size: } 0.3-1.2 \mathrm{~mm}\end{array}$ \\
\hline Duolite A568 & $\begin{array}{l}\text { Rohn and Haas, Chauny, } \\
\text { France }\end{array}$ & $\begin{array}{l}\text { Polymerized phenol-formaldehyde anionic exchange resin, } \\
\text { Particle size: } 0.15-0.85 \mathrm{~mm}\end{array}$ \\
\hline Accurel EP 100 & Akzo, Obernburg, Germany & Macroporous polypropylene, Particle size: $0.6-0.8 \mathrm{~mm}$ \\
\hline
\end{tabular}

2

3 
1 Table 3. Fixation level of PLA2 on different carriers, and corresponding enzyme loading and specific 2 activity.

\begin{tabular}{lcc}
\hline Carrier $^{\mathrm{a}}$ & $\begin{array}{c}\text { Enzyme loading }^{\mathrm{b}} \\
(\mathrm{mg} \text { protein/g support })\end{array}$ & $\begin{array}{c}\text { Specific activity }^{\mathrm{c}} \\
\left(\mu \mathrm{mol} \mathrm{mg}^{-1} \mathrm{~min}^{-1}\right)\end{array}$ \\
\hline Amberlite XAD7 & 49.0 & 0.30 \\
Superlite DAX8 & 44.4 & 0.28 \\
Duolite A568 & 43.3 & - \\
Dowex 50W & 7.8 & - \\
Celite 545 & 3.6 & - \\
Accural EP 100 & 1.9 & - \\
+ Prewetting & 42.5 & - \\
Lewatit VPOC 1600 & 1.3 & - \\
+ Prewetting & 40.3 & \\
\hline
\end{tabular}

3

$4{ }^{a}$ Pre-wetting of Accural EP 100 and Lewatit VPOC 1600 were done by addition of $0.5 \mathrm{ml} 96 \%$ ethanol/ $5 \mathrm{~g}$ support immediately before immobilization; ${ }^{\mathrm{b}}$ Pooled $\mathrm{SD}=1.0 \mathrm{mg}$ protein $/ \mathrm{g}$ support; ${ }^{\mathrm{c}}$ Pooled $\mathrm{SD}=$ $6 \quad 0.015 \mu \mathrm{mol} \mathrm{mg}{ }^{-1} \mathrm{~min}^{-1} ;-$ n.d., not determined. 
1 Table 4 Settings of the RSM generated experimental design for the $\mathrm{PLA}_{2}$ catalyzed acidolysis and 2 measured responses.

\begin{tabular}{|c|c|c|c|c|c|c|c|}
\hline \multirow{2}{*}{ Experiment no. } & \multicolumn{3}{|c|}{ Factors } & \multicolumn{4}{|c|}{ Responses $^{\mathrm{a}}$} \\
\hline & $\mathrm{T}_{\mathrm{e}}$ & $\mathrm{W}_{\mathrm{a}}$ & $\mathrm{S}_{\mathrm{r}}$ & Inc. & $\mathrm{PC}$ & LPC & GPC \\
\hline 1 & 35 & 1 & 6 & 8.0 & 70.0 & 22.1 & 7.9 \\
\hline 2 & 55 & 1 & 6 & 5.9 & 72.1 & 19.8 & 8.1 \\
\hline 3 & 35 & 3 & 6 & 28.3 & 20.6 & 62.4 & 17.0 \\
\hline 4 & 55 & 3 & 6 & 32.9 & 24.1 & 64.9 & 11.0 \\
\hline 5 & 35 & 1 & 12 & 11.3 & 62.4 & 28.1 & 9.5 \\
\hline 6 & 55 & 1 & 12 & 7.2 & 76.0 & 16.8 & 7.2 \\
\hline 7 & 35 & 3 & 12 & 32.1 & 22.4 & 63.8 & 13.8 \\
\hline 8 & 55 & 3 & 12 & 28.6 & 25.1 & 58.3 & 16.6 \\
\hline 9 & 25 & 2 & 9 & 9.8 & 54.8 & 40.2 & 5.0 \\
\hline 10 & 65 & 2 & 9 & 3.1 & 74.0 & 19.4 & 6.6 \\
\hline 11 & 45 & 0 & 9 & 0.6 & 90.0 & 3.0 & 7.0 \\
\hline 12 & 45 & 4 & 9 & 30.5 & 17.7 & 65.0 & 17.3 \\
\hline 13 & 45 & 2 & 3 & 25.3 & 29.2 & 62.3 & 8.5 \\
\hline 14 & 45 & 2 & 15 & 35.0 & 25.2 & 56.2 & 18.6 \\
\hline 15 & 45 & 2 & 9 & 33.5 & 30.7 & 56.4 & 12.9 \\
\hline 16 & 45 & 2 & 9 & 35.9 & 28.7 & 58.3 & 13.0 \\
\hline 17 & 45 & 2 & 9 & 33.5 & 30.3 & 60.4 & 9.3 \\
\hline
\end{tabular}

3

4 Abbreviations: $\mathrm{T}_{\mathrm{e}}$, Reaction temperature $\left({ }^{\circ} \mathrm{C}\right) ; \mathrm{W}_{\mathrm{a}}$, water addition ( $\mathrm{wt} \%$ based on total substrate); $\mathrm{S}_{\mathrm{r}}$, 5 substrate ratio (mol Caprylic acid/mol PC), Inc., Incorporation of caprylic acid (mol\%), PC, 6 phosphatidylcholine content; LPC, lysophosphatidylcholine content; GPC, glycerophosphorylcholine 7 content. ${ }^{\text {a }}$ Values reported for the PL distribution are based on weight percentages of PC + LPC + GPC 
1 Table 5 Regression coefficients and P-values describing the influence of different parameters on

2 incorporation of caprylic acid into PC and PL distribution ${ }^{\mathrm{a}}$.

\begin{tabular}{|c|c|c|c|c|c|c|c|c|}
\hline \multirow[b]{4}{*}{ Term } & \multirow{2}{*}{\multicolumn{2}{|c|}{$\begin{array}{c}\text { Incorporation of caprylic acid } \\
\text { into } \mathrm{PC}(\mathrm{mol} \%)\end{array}$}} & \multicolumn{6}{|c|}{ PL distribution (wt\%) } \\
\hline & & & \multicolumn{2}{|c|}{$\mathrm{PC}$} & \multicolumn{2}{|c|}{ LPC } & \multicolumn{2}{|c|}{ GPC } \\
\hline & Regression & & Regression & & Regression & & Regression & \\
\hline & coefficient & P-value & coefficient & P-value & coefficient & P-value & coefficient & P-value \\
\hline Constant & 32.38 & $9.97 \times 10^{-10}$ & 28.37 & $1.45 \times 10^{-9}$ & 58.72 & $3.58 \times 10^{-12}$ & 12.91 & $9.68 \times 10^{-7}$ \\
\hline $\mathrm{Te}$ & -2.07 & 0.06 & 5.22 & $1.52 \times 10^{-4}$ & -4.81 & $6.95 \times 10^{-4}$ & -0.40 & 0.62 \\
\hline Wa & 8.50 & $5.32 \times 10^{-6}$ & -19.38 & $8.81 \times 10^{-10}$ & 16.55 & $1.32 \times 10^{-8}$ & 2.83 & $5.13 \times 10^{-3}$ \\
\hline Te xTe & -6.51 & $7.83 \times 10^{-6}$ & 8.83 & $2.01 \times 10^{-7}$ & -7.18 & $4.10 \times 10^{-6}$ & -1.65 & 0.03 \\
\hline Wa $\times$ Wa & -4.33 & $2.38 \times 10^{-4}$ & 6.19 & $5.34 \times 10^{-6}$ & -6.16 & $1.59 \times 10^{-5}$ & -0.03 & 0.97 \\
\hline Te $\mathrm{x}$ Wa & 1.87 & 0.22 & -3.72 & 0.02 & 3.60 & 0.03 & 0.12 & 0.92 \\
\hline
\end{tabular}

3

$4 \quad{ }^{\mathrm{a}}$ Values reported for the PL distribution are based on weight percentages of PC + LPC + GPC. The effect

5 of each factor (linear and quadratic) and interaction effects are statistically significant when $\mathrm{P}$-value $<0.05$. 


\section{Figure legend:}

2 Figure 1: Schematic presentation of $\mathrm{PLA}_{2}$-catalyzed acidolysis of phospholipid with free fatty acid. $\mathrm{R}_{1}, \mathrm{R}_{2}$ and $\mathrm{R}_{3}$ refer to fatty acids and $\mathrm{x}$ refers to phospholipid head group (e.g. choline).

Figure 2: Influence of initial enzyme/support ratio on fixation level to Amberlite XAD7. Varying amounts $\mathrm{PLA}_{2}$ were incubated in the presence of 250 mg carrier. Bars represents mean \pm pooled SD.

Figure 3: Bioconversion efficiency of $\mathrm{PLA}_{2}$ immobilized Amberlite XAD7. A) Influence on enzymatic loading on activity and specific activity of immobilized system with different fixation level (mg enzyme per $\mathrm{g}$ support). B) Influence on enzymatic loading on activity and specific activity of immobilized system with same fixation level. Enzymatic assay and $\mathrm{PLA}_{2}$ activity measurement were performed according to procedure described in material and methods. Bars represent mean \pm pooled SD (n=2).

Figure 4: Time course for acidolysis reaction between PC and caprylic acid in solvent free system. Reaction conditions: substrate ratio, $6 \mathrm{~mol} / \mathrm{mol}$ caprylic acid/PC, water addition, $0.75 \%$; dosage of immobilized enzyme, $30 \mathrm{wt} \%$; and reaction temperature, $40^{\circ} \mathrm{C}$. A) Incorporation of caprylic acid into PC and B) PL distribution. Bars represent mean \pm pooled SD $(n=2)$.

Figure 5: Effect of water addition on $\mathrm{PLA}_{2}$ catalyzed acidolysis reaction when varied from low to a high level with all other factors being on their 
average. A) Incorporation of caprylic acid into PC and B) PL distribution. Error bars indicate 95\% confidence interval.

3 Figure 6: Effect of reaction temperature on $\mathrm{PLA}_{2}$ catalyzed acidolysis reaction when varied from low to a high level with all other factors being on their 5 average. A) Incorporation of caprylic acid into PC and B) PL 6 distribution. Bars indicate $95 \%$ confidence interval.

7 
$1 \quad$ Figure 1

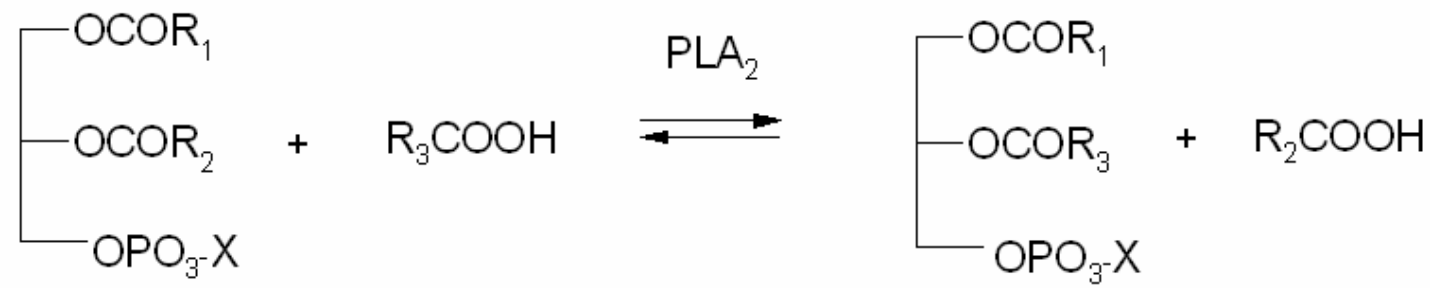

2

3 
$1 \quad$ Figure 2

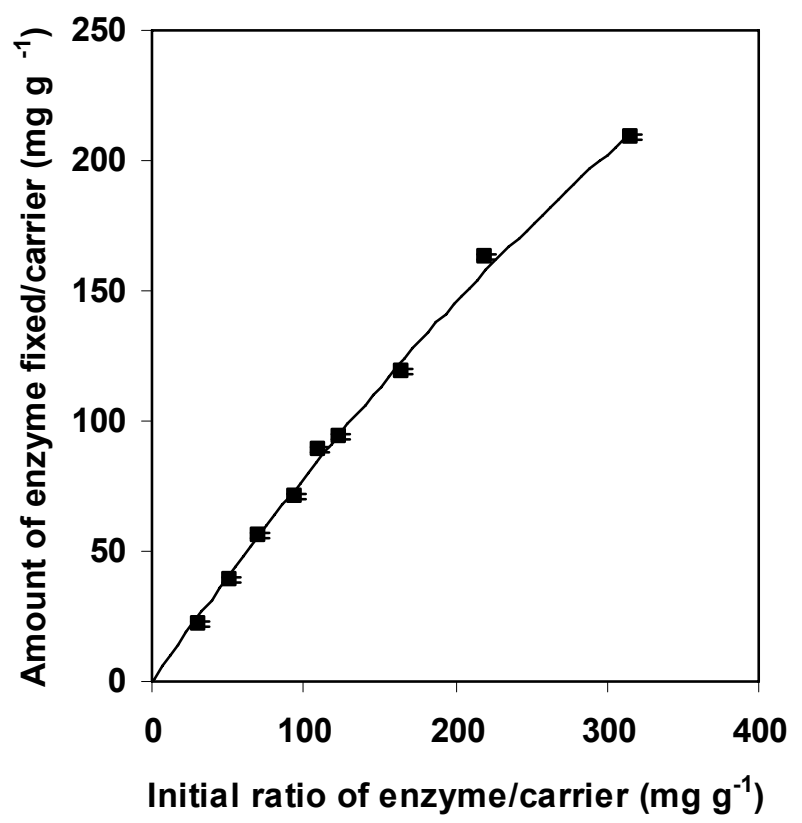

2 
$1 \quad$ Figure 3

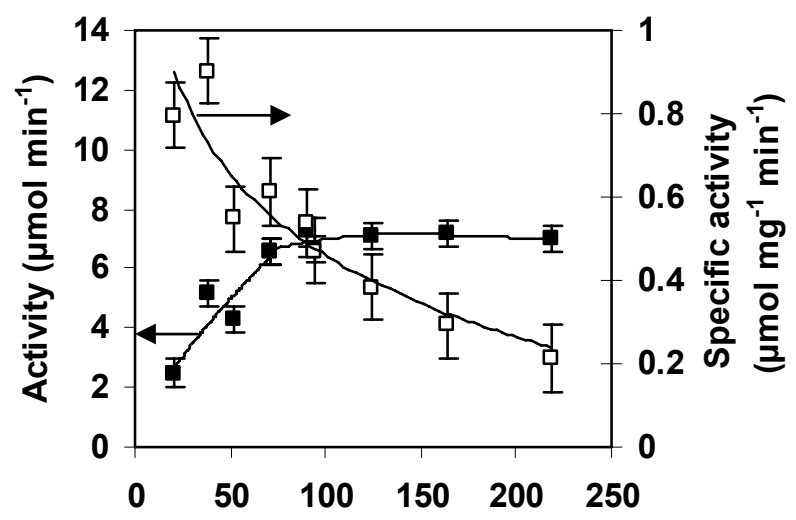

(A) Protein loading $\left(\mathrm{mg} \mathrm{g}^{-1}\right)$

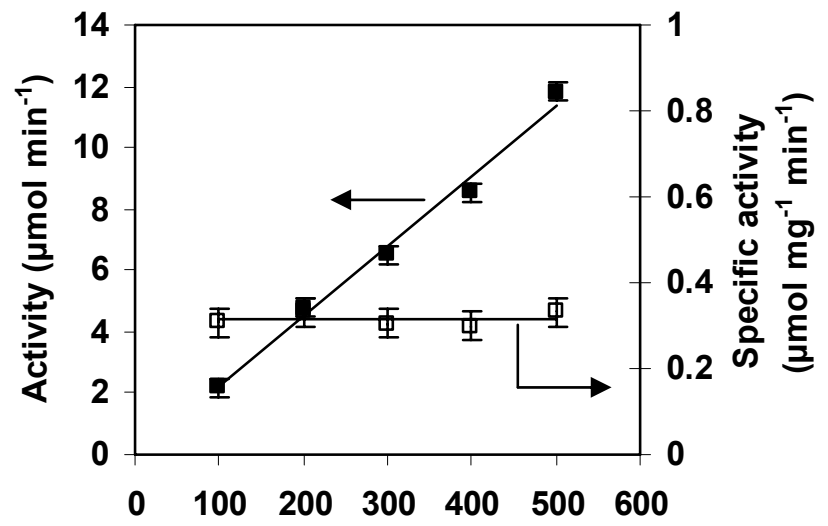

(B) Enzyme dosage (mg) 
$1 \quad$ Figure 4

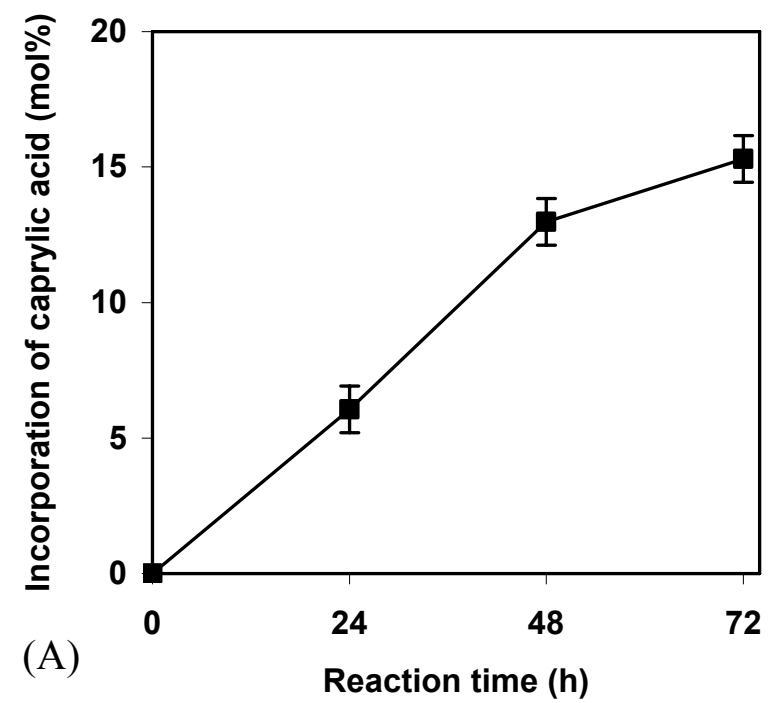

2

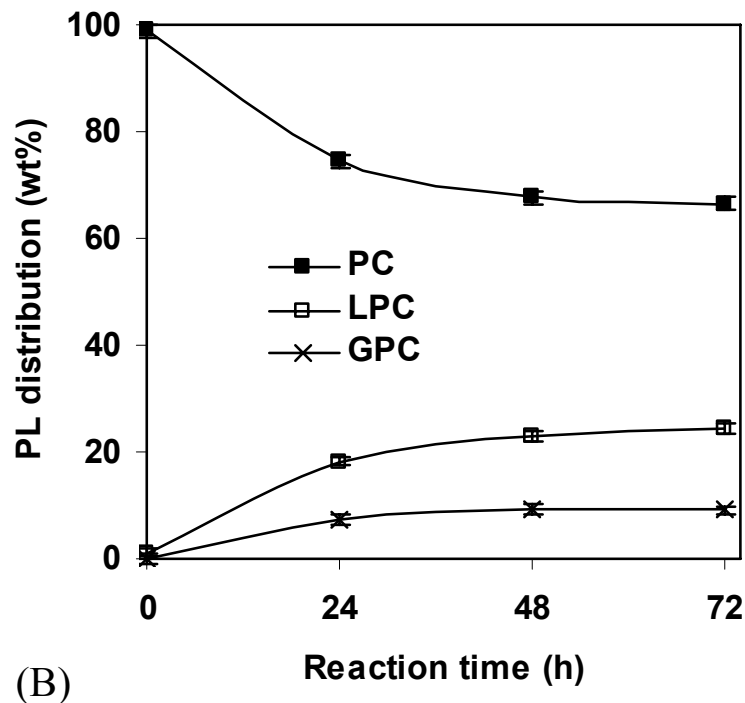

3

4

5

6 
1 Figure 5

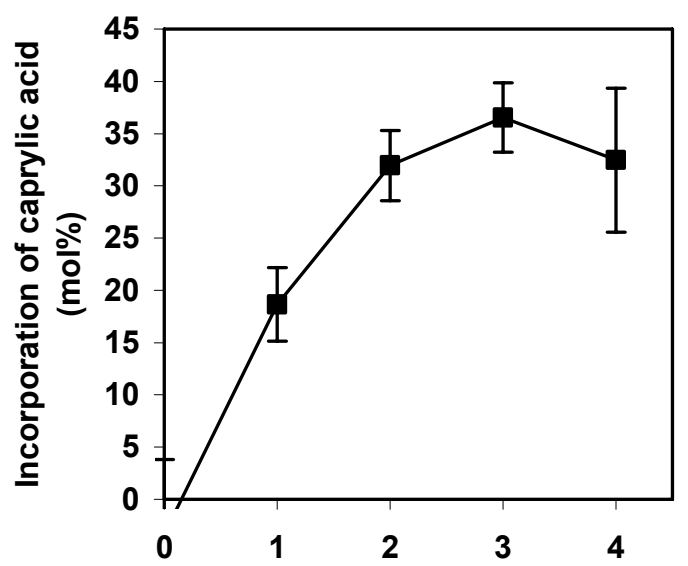

(A) Water addition (\%)

2

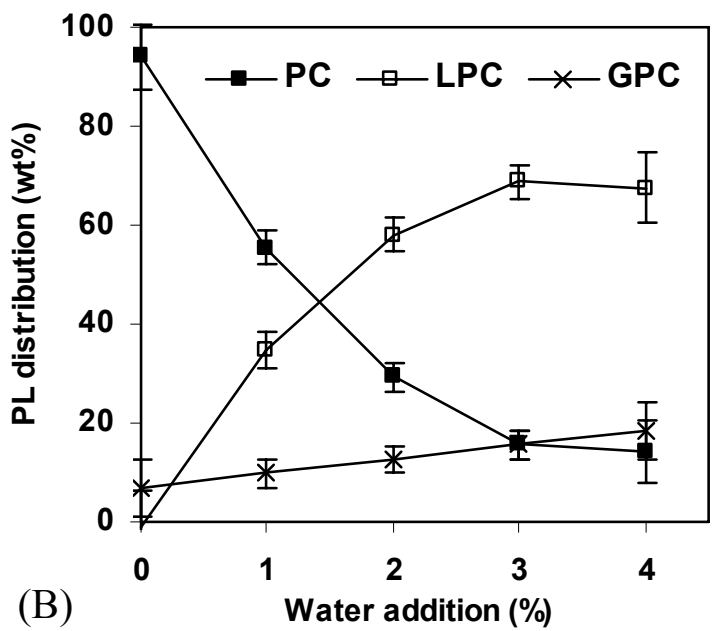

3

4

5

6

7

8

9

10

11 
$1 \quad$ Figure 6

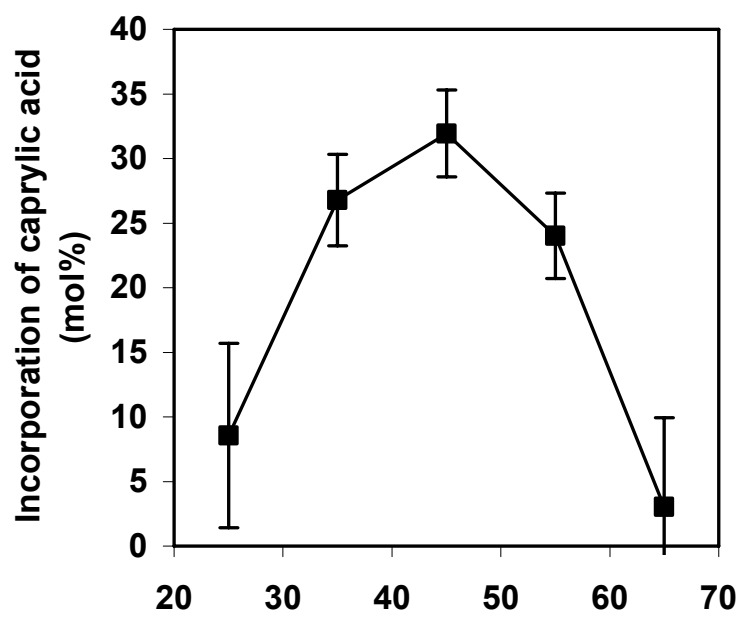

(A) Reaction temperature $\left({ }^{\circ} \mathrm{C}\right)$

2

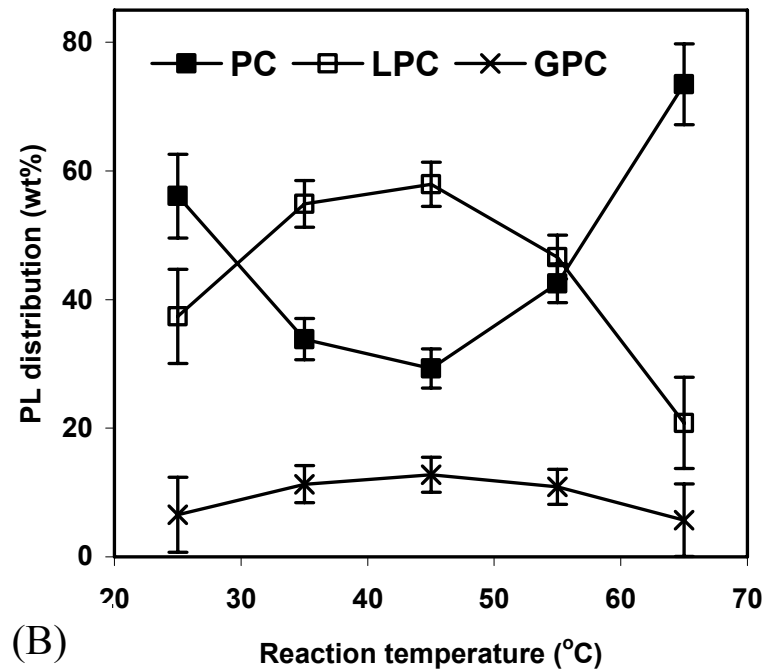

3

4

5

6 